Journal Club

Editor's Note: These short reviews of a recent paper in the Journal, written exclusively by graduate students or postdoctoral fellows, are intended to mimic the journal clubs that exist in your own departments or institutions. For more information on the format and purpose of the Journal Club, please see http://www.jneurosci.org/misc/ifa_features.shtml.

\title{
BARS at the Synapse: PICK-1 Lipid Binding Domain Regulates Targeting, Trafficking, and Synaptic Plasticity
}

\author{
Pamela Arstikaitis and Catherine Gauthier-Campbell \\ Department of Psychiatry and the Brain Research Centre, University of British Columbia, Vancouver, British Columbia, Canada V6T 1Z4 \\ Review of Jin et al. (http://www.jneurosci.org/cgi/content/full/26/9/2380)
}

Targeting of AMPA receptors (AMPARs) to synaptic sites is critical for synaptic plasticity, including long-term potentiation (LTP) and long-term depression (LTD) (Barry and Ziff, 2002; Bredt and Nicoll, 2003). In hippocampal pyramidal neurons, AMPA receptors mediate rapid synaptic transmission. Trafficking of AMPARs to synaptic sites occurs by two main mechanisms: (1) glutamate receptor (GluR)2/3 subunits constitutively cycle to and from the synapse, and (2) GluR1/2 subunits are inserted into the synapse in an activity-dependent manner. A number of proteins regulate the trafficking and insertion of AMPA receptors at synaptic sites, including protein-interacting $\mathrm{C} \mathrm{ki-}$ nase (PICK1). PICK1 is localized to excitatory synapses in cultured hippocampal neurons, and it interacts with the C-terminal PSD-95/Discs large/zona occludens-1 (PDZ) domain of GluR2/3 subunits (Xia et al., 1999). Furthermore, PICK1 promotes colocalization and clustering of AMPA receptors at excitatory sites (Xia et al., 1999). Structurally, PICK1 has multiple domains that function as protein-interaction sites, including a PDZ domain located at the $\mathrm{N}$ terminus, a central Bin/amphiphysin/Rvs (BAR) domain, and an acidic domain. The recent paper by Jin et al. (2006) in The Journal of Neuroscience demonstrates that the PICK1 BAR

Received May 10, 2006; revised May 24, 2006; accepted May 24, 2006.

Correspondence should be addressed to Pamela Arstikaitis at the above address. E-mail: parstika@interchange.ubc.ca.

D01:10.1523/JNEUROSCI.2007-06.2006

Copyright $\odot$ 2006 Society for Neuroscience $\quad$ 0270-6474/06/266909-02\$15.00/0 domain is important for the targeting of PICK1 and expression of LTD. The authors show that PICK1 binds phosphoinositide lipids via the BAR domain and that lipid binding is critical for the synaptic targeting of PICK1, trafficking of AMPA receptors to the membrane surface, and induction of LTD.

Jin et al. (2006) demonstrate that PICK1 binds lipids in vitro via specific residues present in the BAR domain [Jin et al. (2006), theirFig. A, B (http://www.jneurosci. org/cgi/content/full/26/9/2380/F1)]. Using a Sindbis viral expression system, they infected hippocampal neurons and found that mutations in the BAR domain of PICK1 (PICK1 2K-E, PICK1 3K-E, and PICK1 5K-E) impaired its synaptic targeting, as shown by a reduction in the number and intensity of clusters. Furthermore, the PICK1 2KE mutant did not colocalize at excitatory synapses with PSD-95 [Jin et al. (2006), their Fig. A (http://www.jneurosci. org/cgi/content/full/26/9/2380/F4)], suggesting that the lipid-binding domain is important for the synaptic targeting of PICK1.

To explore how mutations in the BAR domain would affect synaptic targeting of GluR1 and GluR2, the authors infected hippocampal neurons with either GFP alone, GFP-PICK1, or GFP-PICK1 2K-E and stained the neurons with either GluR1 or GluR2 antibody [Jin et al. (2006), their Fig. 6A,B (http://www.jneurosci.org/cgi/ content/full/26/9/2380/F6)]. They found that cluster density and intensity for both GluR1 and GluR2 subunits were increased in wild-type GFP-PICK1 but not in GFPPICK1 2K-E, suggesting that the BAR domain may be important for the trafficking of both GluR1 and GluR2 subunits to synapses [Jin et al. (2006), their Fig. 6C,D (http://www.jneurosci.org/cgi/content/ full/26/9/2380/F6)].

Expression of LTD in neurons is thought to result in a loss of AMPA receptors at the plasma membrane. Previous studies by Xia et al. (2000) demonstrated that PICK1 is important for the expression of LTD. Using whole-cell patchclamp recordings in neurons, Jin et al. (2006) found that intracellular perfusion of the BAR mutant PICK1 2K-E increased the EPSC amplitude [Jin et al. (2006), their Fig. $8 A$ (http://www.jneurosci.org/ cgi/content/full/26/9/2380/F8)]. In contrast, application of wild-type PICK1 resulted in no change in EPSC amplitude compared with control. This finding indicates that lipid binding of PICK1 contributes to LTD expression by regulating AMPA receptor trafficking during synaptic plasticity.

LTP and LTD are cellular models underlying learning and memory. Because regulated expression of AMPARs is critical for synaptic plasticity, proteins that control the insertion and internalization of AMPARs are likely to play a role in the molecular mechanisms underlying learning and memory. From the findings in this paper (Jin et al. 2006), modulation of expression, targeting, and trafficking of AMPA receptors by the PICK1 BAR domain may be important for LTD. Indeed, 
the authors show that PICK1 regulates the subunit composition of synaptic receptors by removing GluR2-containing AMPARs from the surface that are then replaced by GluR1-containing receptors (Fig. 1). Interestingly, these effects of PICK1 expression are blocked by a PKC inhibitor, bisindolylmaleimide I, demonstrating that PICK1-dependent removal of GluR2 subunits from the surface requires activation of an endogenous kinase cascade to exert its effects (Terashima et al., 2004).

Palmitoylation, a posttranslational modification, is important for targeting of proteins to synaptic sites (Huang and ElHusseini, 2005). For example, palmitoylation of PSD-95 is important for its synaptic targeting in neurons, and this is regulated in an activity-dependent manner (Huang and El-Husseini, 2005). It would therefore be interesting to investigate whether the BAR domain of PICK1 is regulated by activity and whether this affects the clustering of AMPA receptors. This finding would be significant because it could demonstrate that specific domains are important for activitydependent association of PICK1 with synaptic AMPA receptors.

It is likely that partial or complete potentiation of AMPAR-mediated transmission by PICK1 is attributable to the decrease in the GluR2 content of receptors. However, several questions remain unanswered. First, it is still unclear whether the decrease in GluR2 is accompanied by an upregulation of GluR1 subunit expression. A recent study by Terashima et al. (2004) reported that PICK1 expression had no effect on surface GluR1; however, Jin et al. (2006) show a significant increase in synaptic GluR1 density. Thus, additional studies will be required for understanding the effect of PICK1 in GluR1 trafficking. It is also possible that PICK1 may cause an increase in spine size, allowing the accumulation of more AMPARs at the synapse. Second GluR2 and GluR3 knock-out mice show normal LTD (Meng et al., 2003), which is inconsistent with the simplest interpretation of the data of Jin et al. (2006). Despite having impaired basal synaptic transmission, these mice show no defects in LTD or LTP, suggesting that GluR1/4 alone are capable of multiple forms of synaptic plasticity (Meng et al., 2003). Together, these results indicate the importance of PICK1 in regulating GluR2 expression at synaptic sites and its potential role in controlling molecular mechanisms of synaptic plasticity.

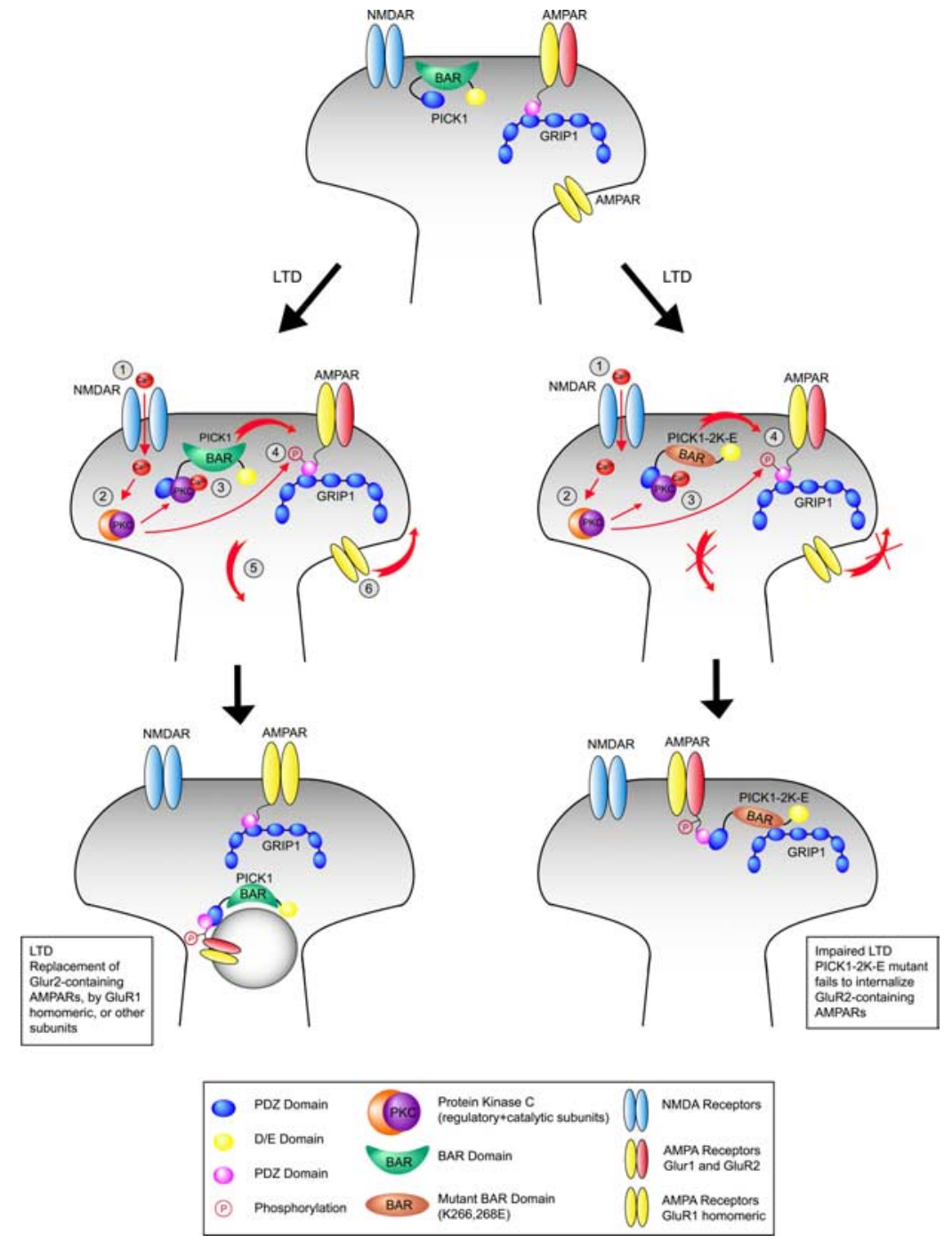

Figure 1. A model to illustrate how PICK1 (green) maintains an intracellular reserve pool of AMPA receptors at the synapse by binding to negatively charged lipids. LTD protocols that cause an influx of calcium ions (1) through NMDA receptors (blue) lead to the activation of PKC (2) (regulatory subunit: orange, catalytic subunit: purple). Binding of PKC to PICK1 (3) and phosphorylation of GluR2 at serine 880 by PKC (4) causes GluR2 subunits to preferentially bind PICK1. Dissociation of GluR2 from glutamate receptor-interacting protein (GRIP1) leads to the internalization of GluR2 containing AMPA receptors (red and yellow) through the association of the PICK1 BAR domain with lipids of endocytic vesicles (5). Extrasynaptic AMPA receptors, including GluR1 homomeric receptors (yellow), move laterally to the synaptic surface to replace the internalized receptors and bind GRIP1 (6). The end result of long-term depression is a decrease in the total GluR2-containing AMPA receptors at the synapses. Although both GluR1 and GluR2 are decreased within synapses, their distribution at the surface could be differentially modulated by PICK1. In contrast, mutations in the BAR domain of PICK1 (brown) prevent its association with lipids; hence, PICK1 2K-E cannot internalize GluR2 containing AMPA receptors from the synaptic surface.

\section{References}

Barry MF, Ziff EB (2002) Receptor trafficking and the plasticity of excitatory synapses. Curr Opin Neurobiol 12:279-286.

Bredt DS, Nicoll RA (2003) AMPA receptor trafficking at excitatory synapses. Neuron 40:361-379.

Huang K, El-Husseini A (2005) Modulation of neuronal protein trafficking and function by palmitoylation. Curr Opin Neurobiol 15:527-535.

Jin W, Ge W-P, Xu J, Cao M, Peng L, Yung W, Liao D, Duan S, Zhang M, Xia J (2006) Lipid binding regulates synaptic targeting of PICK1, AMPA receptor trafficking, and synaptic plasticity. J Neurosci 26:2380-2390.

Meng Y, Zhang Y, Jia Z (2003) Synaptic trans- mission and plasticity in the absence of AMPA glutamate receptor GluR2 and GluR3. Neuron 39:163-176.

Terashima A, Cotton L, Dev KK, Meyer G, Zaman S, Duprat F, Henley JM, Collingridge GL, Isaac JT (2004) Regulation of synaptic strength and AMPA receptor subunit composition by PICK1. J Neurosci 24:5381-5390.

Xia J, Zhang X, Staudinger J, Huganir RL (1999) Clustering of AMPA receptors by the synaptic PDZ domain-containing protein PICK1. Neuron 22:179-187.

Xia J, Chung HJ, Wihler C, Huganir RL, Linden DJ (2000) Cerebellar long-term depression requires $\mathrm{PKC}$-regulated interactions between GluR2/3 and PDZ domain-containing proteins. Neuron 28:499-510. 